\title{
Familias homoparentales: ¿Reproducción o transgresión del género hegemónico?
}

\author{
Homoparental families: Reproduction or trangression of the \\ hegemonic genre?
}

María Angélica Cruz ${ }^{*}$

Marian Llantén Oyarce **

\section{Resumen:}

En este artículo buscamos, primero, comprender cómo las familias homoparentales reproducen y/o tensionan las normas hegemónicas del género y, segundo, si ello cambia al participar en colectivos del movimiento homosexual. Metodológicamente trabajamos con entrevistas a un grupo de adultos de este tipo de familias. Los resultados muestran múltiples trayectorias para llegar a ser familias homoparentales y distintos modos de (in)visibilizarlas. En todas ellas el género hegemónico se reproduce buscando garantizar el bienestar de los/as hijos/as; no obstante, entre quienes participan en colectivos encontramos ciertas prácticas que lo tensionan o desacatan, particularmente en casos de maternidades lésbicas asistidas tecnológicamente. Así, concluimos que la sola existencia de familias homoparentales cuestiona los supuestos básicos sobre la sexualidad y el género, pero ello no garantiza la transgresión del orden hegemónico del género.

Palabras clave: familia, homoparentalidad, prácticas políticas, normas de género, heteronormatividad

\footnotetext{
Abstract:

* Socióloga, por la Universidad de Chile. Doctora en Sociología, Universidad Complutense de Madrid. Profesora Titular Universidad de Valparaíso. Docente sobre metodologías de investigación social y seminarios de titulación. Sus líneas de investigación corresponden a memorias sociales de la dictadura, epistemología feminista, género y prácticas políticas. Investigadora Responsable Proyecto Fondecyt 11150115.

${ }^{* *}$ Socióloga, por la Universidad de Valparaíso. Experiencia profesional en investigación cualitativa y evaluación de proyectos sociales. Asistente de investigación para proyecto Fondecyt 11150115 (2016). Actualmente cursa el Magíster Estudios de Mujeres, Género y Ciudadanía en la Universidad de Barcelona

- Parte de este trabajo fue financiado por CONICYT PFCHA/MAGISTER EN EL EXTRANJERO BECAS CHILE/2017- 73180899 y por el proyecto Fondecyt Iniciación 11150115
} 
In this article we aim to, first, understand the way homoparental families reproduce and/or tense hegemonic norms about gender and, second, whether that changes by participating in the homosexual movement. We interview a group of adults from these families. The results show multiple trajectories towards coming to be such, and different ways of making them invisible. In all of these trajectories, the hegemonic norm of gender its reproduced while trying to make sure the childrens' wellbeing. However, among those who are part of organized groups, we can find certain practices that tense those norms, especially in cases of lesbian mothers with technological assistance. Thus, we conclude that the sole existence of homoparental families questions the basic assumptions about sexuality and gender, but they do not guarantee the transgression of the hegemonic gender norms.

Key words: family, homoparentality, political practices, gender norms, heteronormativity

Fecha de recepción: 29 de mayo 2017

Fecha de aprobación: 30 de mayo 2018

\section{Introducción}

Como se sabe, los múltiples procesos de modernización de las últimas décadas han transformado las diversas instituciones sociales, entre ellas la familia. En Latinoamérica la familia ha pasado de un modelo moderno-industrial a uno relacional (Valdés, 2006). En este último, la lógica de los sentimientos y las relaciones afectivas son priorizadas por sobre las normas morales e institucionales.

En ese marco, las familias homoparentales se convierten en un desafío frente a los modelos más tradicionales de familia, logrando por su sola existencia, deconstruir el concepto más arraigado de familia que la sitúa siempre definida a partir de un vínculo basado en relaciones de pareja y parentalidad heterosexual, alterando la norma de identidad sexual como sinónimo de la relación entre un hombre y una mujer.

A su vez, la politización de nuevas formas de familia, incluyendo las basadas en la homoparentalidad, ha sido impulsada por los movimientos sociales feministas y de minorías sexuales. $Y$ aunque hemos sido testigos de avances en este campo, la sociedad chilena aún está en deuda con las demandas que tales formas de acción política han impulsado.

En Chile, la Ley de Unión Civil es considerada el primer hito del reconocimiento legal a la unión de parejas del mismo sexo, así como también a las uniones heterosexuales que no optan por el matrimonio. Dicha ley fue promulgada en abril de 2015 y, a contar del día 22 de octubre del mismo año pudieron llevarse a cabo las primeras uniones civiles. EI AUC (Acuerdo de Unión Civil) permite que los convivientes de igual o distinto sexo regulen su unión, a través de una ceremonia que otorga el estado civil de Conviviente Civil, y reconoce los vínculos similares 
Revista Punto Género N.ำ 9. Junio de 2018

ISSN 0719-0417 / 85 - 105

contraídos en el extranjero (MOVILH, 2014).

En cuanto a las demandas vinculadas con la parentalidad, una de las críticas realizadas a la Ley Antidiscriminación, fue la nula presencia de la homoparentalidad en el proyecto, considerando, por ejemplo, la tuición y su vinculación exclusiva con la heterosexualidad. Esto llevó a presentar modificaciones al Código Civil, vinculadas con garantizar que ningún padre 0 madre pueda perder a sus hijos/as por razones relacionadas con su orientación sexual o identidad de género. En lo que respecta al Acuerdo de Unión Civil, sólo se menciona, en relación a la crianza, que:

"Podrá el juez, en caso de inhabilidad física o moral de ambos padres, confiar el cuidado personal de los hijos a otra persona o personas competentes, velando primordialmente por el interés superior del niño (...) En la elección de estas personas se preferirá a los consanguíneos más próximos y, en especial, a los ascendientes, al cónyuge o al conviviente civil del padre o madre, según corresponda" (MOVILH, 2014: 143-144).

Con todo, las familias homoparentales existen, aunque generalmente son más bien invisibles. Por lo mismo, poco sabemos acerca de cómo viven el ser familia, desde unos vínculos que, en la práctica, transgreden las reglas heteronormativas de género, pero que no por ello necesariamente logran transformar ciertos sentidos que están encarnados, en tanto el género no responde solo a significaciones abstractas, sino que se hace carne y se pone en acto ${ }^{1}$. Con ello en mente, realizamos una investigación, conducente a una memoria de grado en sociología (2012-2015), cuyo objetivo era comprender cómo las familias homoparentales significan a la familia en la actualidad, en el marco de las reivindicaciones vinculadas con la unión homosexual y la parentalidad.

En este artículo, presentamos un nuevo análisis de parte de los resultados de esa tesis ${ }^{2}$, buscando mostrar, primero, cómo los adultos de las familias homoparentales reproducen o tensionan las normas hegemónicas del género, en sus formas de entender lo que es una familia y segundo, cómo ello cambia, o no, cuando se es parte de colectivos que defienden los

\footnotetext{
${ }^{1}$ En términos religiosos la encarnación alude al hecho de que un ser espiritual adopta una forma carnal. Desde la teoría feminista se la usa como metáfora para apartarse de la idea clásica del género asumido en tanto construcción socio cultural que deja al sexo ubicado en lo pre-existente. De este modo, entendemos el género en su dimensión semiótico-material, pero asumiendo, además, que la materialidad no es sinónimo de usar la corporalidad como fundamento de identidades esencialistas, ni tampoco dentro de los límites del cuerpo humano sino en su relación con diversas formas no humanas. Así, con Haraway, comprendemos que la encarnación feminista no trata de "localizaciones fijas" en cuerpos reificados, sino de "nudos en campos, inflexiones y orientaciones y de responsabilidad por la diferencia en campos material-semióticos de significados" (Haraway, 1995: 334). Del mismo modo, se trata de encarnaciones situadas en unas coordenadas socio-históricas y cuyo carácter es siempre híbrido y relacional (Cruz, 2015).

2 Tesis de pregrado en sociología realizada por Marián Llantén: "Familias Homoparentales en Chile: Estudio cualitativo acerca las familias homoparentales en Chile y el significado que le otorgan a ésta en la actualidad, en el marco de las reivindicaciones vinculadas con la unión homosexual y la parentalidad"; guiada por María Angélica Cruz, y aprobada en mayo de 2016.
} 
derechos LGBTI.

En base a narrativas construidas en el contexto de entrevistas abiertas, los adultos de diversas familias homoparentales, de Santiago y Valparaíso, nos compartieron extractos de su historia acerca de cómo llegaron a ser familia. Entre ellas y ellos hay quienes, además de reconocerse desde una identidad no heterosexual, exigen el reconocimiento de sus derechos participando en colectivos y organizaciones que trabajan por los derechos de la comunidad LGBTI. Ese tipo de participación supone formas de politización que transforman el concepto de familia en el cual fueron socializados; sin embargo, pese al activismo, no pueden escapar del todo a las nociones tradicionales que esta institución sigue reproduciendo.

Así, este trabajo se enfoca en cómo se reproducen y/o tensionan los mandatos de género en las familias homoparentales, particularmente en lo que respecta a los elementos y formas más heteronormativas de la familia, y cómo esto se vincula con las prácticas políticas de aquellas familias más activas respecto del movimiento social de liberación homosexual. Buscamos responder interrogantes sobre ¿Cómo se estructuran las posiciones al interior de la familia? ¿Cómo se posicionan respecto de su entorno? ¿Cómo construyen los conceptos de ser hombre y mujer al interior de sus familias? $Y$, en particular, si las respuestas a estas preguntas adquieren alguna particularidad cuando se participa activamente en organizaciones y colectivos del movimiento homosexual.

\section{Enfoque Teórico}

\subsection{El género y la transformación del concepto de familia:}

La categoría de género emerge en los años 60, ante la necesidad de visibilizar los aspectos estructurales y sociales de la opresión de las mujeres, más allá de sus características biológicas. Sin embargo, según Casado (2003), toma rápidamente la forma de un fundamento trans-histórico que descansa en explicar la sujeción femenina por la sujeción misma, según Butler, sin explorar la forma en que feminidad y masculinidad se actualizan en cada contexto y modifican, por lo tanto, el género como norma ${ }^{3}$. Entendiendo el género en términos

3 Siguiendo a Butler (2006), entendemos el género en tanto norma en el sentido que está sujeto a diversas regulaciones a través de distintos tipos de políticas y reglas; pero esa regulación no opera sólo como un proceso abstracto sino material, ni tampoco se limita a la mera imposición de reglas sino que ellas son incorporadas, vividas y alteradas por los sujetos a través de sus prácticas corporeizadas. Nada de esto supone que el sujeto y el género preexistan a su regulación, se trata más bien de entender los procesos de sujeción como la operación a través de la cual el género es producido por la regulación. A su vez, a partir del reconocimiento de que todo conocimiento es situado, la localización nos obliga a no evadir la pregunta por el tipo de mundos con el que cual nos comprometemos. Así, la búsqueda de nuevos puntos de vista relevantes en nuestra cultura tecnocientífica, se apoya en las posiciones monstruosas -ya no solo subalternas- de quienes no encajan con la norma. Para analizar el poder en la ciencia y la tecnología, podemos detenernos en cómo las normas producen un tipo de trabajo invisible para ciertas personas, al tiempo que aclaran el camino para otras, cómo determinadas identidades consolidadas para algunas posiciones producen localizaciones marginales para otras. A ello se dirige el punto de vista "cyborg" de Star: "la relación entre tecnologías estandarizadas y experiencia local" donde 
situacionales (Haraway, 2004), nos preguntamos por cómo éste "trabaja" más que por lo que "es", poniendo atención a la materialidad de sus actualizaciones (Cruz, 2015). Esto conlleva "entender" la pregunta por las identidades de género alejadas de las conceptualizaciones donde la identidad precede a las relaciones en las que se inscriben (Romero, 2006). En tal sentido, y siguiendo a De Lauretis, Butler y Braidotti, el género viene a ser una tecnología del self y una ficción reguladora, una "actividad normativa que construye categorías como sujeto, objeto, masculino, femenino, heterosexual/lesbiana como parte del mismo proceso" (Casado, 2003 citado por Cruz, 2015: 3).

La familia, en tanto institución social, es considerada el núcleo fundamental de la sociedad occidental y parte de un conjunto macro-social que posee importantes funciones. Entendemos familia como "una estructura que da vida y forma a un sistema social, ya que en ella los individuos interiorizan el papel que cada uno debe desempeñar en determinado subsistema" (González, 2007:21). Como toda institución social, la familia es parte de la sociedad y está siendo constantemente construida por ella, por tanto, su definición obedece a los contextos en los que la sociedad y la cultura se vienen desenvolviendo. El parentesco ${ }^{4}$ y la institución familiar se desarrollan "producto de su propia articulación con el escenario social, local y específico en el que existe, pues éste no sólo condiciona sus prácticas concretas sino también las formas de pensar, representar y hablar del universo familiar" (Gonzálvez, 2013: 93).

Este proceso ha permitido la visibilización de una variedad de tipos de familias -entre ellas las homoparentales- formadas en base a redes de relaciones íntimas entre personas. Aquí, destaca el reconocimiento de la libertad de elección individual al momento de formar una pareja, entendiendo que se ha pasado del interés familiar a la afirmación de la importancia de los sentimientos individuales. "Las afinidades electivas son principalmente subjetivas y basadas en el sentimiento. Este principio de libertad individual ha cambiado la duración del matrimonio. El derecho a formar una familia deviene universal y se pluraliza" (Bestard y Roigé, 2014:206)

uno llega a insertarse entre ciertas categorías, pero siempre en relación a ellas (Star, 1991: 39 en Haraway, 2004: 56).

${ }^{6}$ Para Pichardo (2009), el parentesco responde a la necesidad de garantizar la supervivencia humana, bajo lo cual se han organizado en diversas culturas, aspectos como la reproducción biológica y social, la división sexual del trabajo, la organización de la residencia, la alimentación o el consumo. Hasta la década de los 80 , el concepto de parentesco predominante en la antropología se caracterizaba por la importancia de los vínculos biológicos, en donde "la familia era entendida desde un modelo biologicista, en el que la sexualidad reproductiva se comprendía en el marco del matrimonio" (Ortiz y Gonzálvez, 2017:61). Sin embargo, el feminismo ha criticado el origen clásico del parentesco, señalando este concepto como "un aspecto de un sistema mayor de desigualdad donde el género se consideraba una dimensión clave" (Gonzálvez, 2013:103). Cuestionaron la primacía de la esfera doméstica organizada bajo elementos afectivos y morales, producto de los vínculos madre-hijos/as, y cuyas otras funciones (económicas, políticas, ideológicas), se continuaban incluyendo sin producirse cambios en su rol primario y naturalizado de reproducción humana. Desde una mirada constructivista, la filiación y afinidad son lazos de parentesco que se alejan de lo referido al nacimiento y se considera su conformación a partir de actos deliberados de alimentación, afecto y cuidado. "La acción de compartir afectos, memorias y cuidados se pone en el centro del parentesco. En este modelo constructivista el cuidado aparece como el hecho constitutivo de la consanguinidad humana” (Bestard, 2009: 87 en Gonzálvez, 2013: 109). 
Asumir y declarar una identidad homosexual, en muchos casos, aun es considerado un rechazo a la familia 5 . Dichas representaciones, parten de la presuposición de que "los homosexuales no aman ni trabajan" (Wiensen Cook, 1977: 48; en Weston, 2003:53), cuestión que reduce a la comunidad homosexual exclusivamente a su identidad sexual y la identidad sexual exclusivamente al sexo.

"Afirmar que las personas heterosexuales acceden de un modo <natural> a la familia, en tanto que los homosexuales están condenados a un futuro de soledad y aislamiento, es no solamente vincular estrechamente el parentesco con la procreación, sino también ver a los gays y las lesbianas como miembros de una especie incapaz de procrear, separada del resto de la humanidad" (Weston, 2003: 53).

No obstante, las acciones tanto individuales como colectivas de personas homosexuales, y sus reivindicaciones relacionadas con el reconocimiento de sus relaciones sexo-afectivas en el marco legal y social del matrimonio, han conllevado la visibilización de modelos de representación y organización social que incorporan nuevos significados acerca de la familia y el matrimonio. Esto permite que la heteronormatividad deje de ser imprescindible para la constitución de esta institución, y da pie al desarrollo de medios "para que las personas homosexuales puedan pensarse al margen de la presunción de heterosexualidad que de algún modo u otro ha estado presente en sus vidas" (Pichardo, 2009: 150).

\subsection{Movimientos sociales, participación y construcciones sociales de género:}

Los significados asociados a la familia se han venido modificando también gracias a los aportes de los movimientos sociales, principalmente feministas y de diversidad sexual. Para Vaggione (2008), estos movimientos han buscado la desinstitucionalización del tradicional concepto de familia, considerando que, desde hace décadas, el universo privado, ubicado en nuevos contextos de discusión por parte de los movimientos sociales, se ha vuelto objeto de intervención política. La participación política contemporánea incluye tanto formas de participación convencionales, que remiten a la lógica de la representación, como también formas no convencionales. Así, las prácticas ya no quedan restringidas a un conjunto de

\footnotetext{
5"La visión esencialista que define las conexiones biológicas como los elementos originarios y constitutivos de las relaciones de parentesco están en la base de los presupuestos legales de la mayoría de los sistemas jurídicos occidentales que regulan el nacimiento y la filiación" (Jociles y Rivas, 2017: 74). Los lazos sanguíneos, diferentes de los lazos de afinidad por ser imborrables, establecen relaciones exclusivas y excluyentes en las que cada persona ocupa una posición de hijo/a en relación a un solo hombre y una sola mujer. En cuanto a las nociones de familia en el marco legal chileno, Ortiz y Gonzálvez (2017) reconocen la existencia de límites que definen claramente quiénes son y no son familia, afirmando que la normativa legal promueve un tipo de familia que se basa exclusivamente en el lazo sanguíneo, la convivencia en un mismo espacio físico y el matrimonio. Sin embargo, en base a las entrevistas realizadas a un grupo de familias de Santiago, las autoras consideran fundamental incluir otros criterios en la definición de sus grupos familiares, entre ellos, "afectos y cuidados mutuos de forma habitual (...), una comunicación constante, la convivencia cotidiana en un mismo espacio físico, compartir tradiciones $y$, en algunas ocasiones, la sensación de deber ser que acompaña algunos vínculos familiares" (Ortiz y Gonzálvez, 2017: 72).
} 
Revista Punto Género N.ำ 9. Junio de 2018 ISSN 0719-0417 / 85 - 105

derechos públicos que responden a un acuerdo entre hombres libres e iguales en estatus y deberes, sino que se comienza a abrir camino a la diversidad para el reconocimiento de las distintas identidades que constituyen la ciudadanía moderna.

En lo que respecta al reconocimiento de la diversidad familiar, este surge como un discurso social e individual al mismo tiempo, "colectivamente construido e introyectado por los sujetos" (Sarti, 1998:11). La familia se define por medio de una relación dialéctica entre un discurso social y su traducción individual y particular. Esta noción de familia - social e individual al mismo tiempo - permite pensar en un universo de afectos y derechos. Esto, debido a que es en la familia en donde se establecen las condiciones básicas para la construcción del otro:

"La familia comporta, por definición, el Otro en sus relaciones. Más precisamente, la familia es estructurante de la noción del Otro. Precisamente porque es en el ámbito familiar que se elaboran las condiciones básicas para la construcción de la noción del Otro, que hay una estrecha relación entre la familia y la construcción de la noción de ciudadanía, del reconocimiento en el plano social de la existencia del Otro" (Sarti, 1998:12).

Para que una sociedad logre llevar adelante un proyecto democrático de relaciones sociales, las condiciones deben estar fuertemente vinculadas a las posibilidades subjetivas de sus ciudadanos, y esta ciudadanía es también una cuestión que se relaciona con la construcción de los afectos. En este sentido, sin que las luchas por la libertad y la igualdad hayan desaparecido en países como los nuestros, se ha sumado un principio de acción colectiva, definido desde el principio de la felicidad, de la autorrealización, o de la calidad de vida. Este nuevo tema toma gran relevancia en las formas de acción colectiva y política que ponen en la mesa movimientos como los feministas y de diversidad sexual, entre otros. Son los actores sociales los encargados tanto de sacar a la luz las demandas por la libertad, como también de exigir el derecho a ser reconocidos legalmente en tanto familia, a partir de la protección y el reconocimiento de derechos sociales y civiles relacionados con la propia manera de organizar las dimensiones afectivas de la vida.

"Se amplían demandas por la autodeterminación en la organización del universo privado, en lo que respecta a las formas de establecimiento de ese universo: conyugalidades fundadas o no en la diferencia de sexo, lazos parentales y de filiación fundados o no en la sangre o en la adopción" (Thurler, 2008:11).

A partir de la llegada de la segunda ola del feminismo y del movimiento gay y de lesbianas, surge un nuevo campo de investigación en el cual se relacionan por un lado, el mundo público de la vida social y, por otro, el mundo de la vida privada y personal, que aparecen de forma simultánea como nuevos campos importantes para la investigación sociológica, y que van desde la violencia doméstica/sexual y los derechos reproductivos, hasta las políticas de identidad y discriminaciones de género/sexuales. Este nuevo campo de investigación y también de práctica política, crece de forma paralela al surgimiento de una serie de prácticas sociales propias del cambio de siglo, las que Plummer agrupa bajo el lema: ciudadanía íntima. Este concepto: 
"aglutina una pluralidad de historias y de discursos públicos acerca de cómo vivir la vida personal en el mundo postmoderno, donde cada vez más hemos de afrontar una diversidad cada vez mayor de opciones y dificultades acerca de cómo construir nuestra intimidad" (Plummer, 2003: 26).

La ciudadanía íntima reúne derechos, obligaciones, procesos de reconocimiento y de respeto, referentes a las esferas más íntimas de la vida, buscando crear la sensación de que las diferentes situaciones se encuentran inextricablemente unidas a la permanencia de diversos grupos y comunidades, lo que provocó sus propias tensiones. "Reconoce que lo particular habita siempre en un contexto universal cambiante. $Y$ todo ello significa que estamos rodeados de conflictos con los que hemos de aprender a vivir, porque no siempre podremos disponer de soluciones evidentes" (Plummer, 2003: 27).

Se habla así de una nueva y emergente forma cultural y de vida, y se centra particularmente en lo referente a las decisiones individuales:

"Decidir con quién casarnos y cuándo divorciarnos; elegir cuántos hijos deseamos tener, si abortamos o si vamos a recurrir a la fecundidad artificial; escoger qué tipo de relación vamos a adoptar o con quién - ya sea homosexual, heterosexual, bisexual o multisexual -; decidir si queremos comportarnos como un hombre, una mujer o incluso como transgéneros, (...) incluso, qué tipo de cuerpo tenemos" (Plummer, 2003:28).

\section{Marco Metodológico}

El universo empírico del estudio, corresponde a los adultos/as de familias homoparentales gays y lesbianas - residentes en las regiones de Valparaíso y Santiago, con y sin participación en actos y organizaciones vinculados al movimiento LGBTI.

La muestra seleccionada, consistió en un total de 8 familias desglosadas en 3 familias de padres gay (2 monoparentales y 1 biparentales), 4 familias con madres lesbianas (1 monoparental y 3 biparentales), 1 familia co-parental, compuesta por una madre y un padre homosexuales, quienes mantienen una relación de amistad.

La investigación trabajó en base a entrevistas abiertas, en el marco de una tesis de pregrado en sociología, que se preguntaba acerca de la transformación del concepto de familia, a la luz de demandas vinculadas con la unión homosexual, la parentalidad y la adopción. Las entrevistas se realizaron en el período 2012-2013. Para efectos de este artículo los resultados han sido tratados como datos secundarios para una nueva interpretación sobre la (re)producción de las normas hegemónicas del género desde las prácticas políticas del presente, en el marco del proyecto Fondecyt N. o 11150115 (2015-2018).

Respecto de la técnica de análisis, se utilizó el "Análisis Sociológico del Discurso" método que, utiliza tres niveles de análisis: textual, contextual e interpretativo. Junto con esto, es importante 
también definir la conexión de los discursos analizados y la realidad social de donde provienen. Según Ruiz (2009), el análisis del discurso se relaciona con un proceso circular y bidireccional que es entendido como concluido al momento en que se considera que los objetivos del estudio han sido logrados.

Con relación al contacto y acceso a los/as entrevistados/as se trató de un proceso lento y difícil, sobre todo en el caso de las madres lesbianas. La mayoría de las reuniones debieron ser concertadas con semanas de anticipación, luego del envío constante de correos electrónicos a nuestros/as entrevistados/as. Principalmente, las familias biparentales coincidieron en consultar con calma a sus parejas e hijos/as la posibilidad de entregar su testimonio antes de aceptar ser entrevistadas. Con todo, se trabajó sobre la base de un pacto de anonimato y consentimiento informado.

\section{Resultados: Trayectorias de familias homoparentales y las normas del orden hegemónico de género.}

\subsection{Familias que no participan en el movimiento LGBTI y la reproducción de las normas de género.}

En nuestra investigación, lo común a las familias que manifiestan no participar de ninguna manera en movimientos LGBTI y/o en formas de protesta enfocadas en visibilizar algunas demandas de dicho movimiento, es que sus discursos, y sobre todo sus prácticas cotidianas, muestran cómo el género es reproducido en su forma más tradicional.

Una de las maneras en que esto opera es a través del intento de entregar a los/as hijos/as una forma de familia nuclear tradicional, vale decir, con la presencia - al menos en los primeros años de vida de los hijos/as - de una imagen paterna masculina y una imagen materna femenina permanentes. Juan, por ejemplo, es un hombre homosexual con una carrera universitaria próspera y estabilidad económica. Lo anterior le permite llevar a cabo su deseo de ser padre en co-parentalidad con una mujer lesbiana inseminada artificialmente por él. Ella también quería convertirse en madre. Dicha asociación, les permitiría a ambos mantenerse cerca de la hija que vendría en camino, sin que tuvieran que relacionarse sentimentalmente como pareja.

"Me dice: "ya tengo treinta años o treintaiuno y también quiero ser mamá y veo que tú eres responsable, tienes tus cosas, una vida estable". Ella era lesbiana y era mejor porque nosotros no íbamos a tener una relación emocional, no había por qué" (Juan, 38 años)

Ambos coincidieron en que la decisión de vivir juntos era también lo mejor para la menor, y en este sentido, es posible distinguir en su discurso el intento de imitar el modelo más tradicional de la familia nuclear heterosexual, con el fin de poder entregar una crianza en un contexto 
descrito por él mismo, como de mayor normalidad. Pero también, para evitar la posibilidad de que su hija en un futuro pudiera sufrir algún tipo de discriminación.

"Íbamos a vivir siempre juntos, los dos íbamos a estar y le íbamos a dar una crianza como un modelo paternal, con una mamá y un papá y que iban a estar dentro de una familia, cosa que a la niña no le faltara por lo menos esos dos pilares fundamentales dentro de lo que es más o menos normal" (Andrés, 38 años, Ingeniero Ambiental).

Lo anterior permite afirmar que aunque los sujetos convivan dentro de un contexto familiar subalterno, constantemente buscan adherirse al modelo de familia más tradicional y normalizado, bajo la intensión de otorgar estabilidad y normalidad a sus hijos e hijas, pero también de evitar la posibilidad de enfrentarlos a posibles episodios de discriminación. Así, aunque su convivencia sigue estando fuera de lo que es considerado más habitual, continúa siendo importante para ellos, por ejemplo, la presencia de una mujer y un hombre como pilares fundamentales de la institución de la familia. Esto, bajo la premisa de presentar a sus hijos/as, modelos de comportamiento femeninos y masculinos tradicionales.

Otra forma en que la norma hegemónica se reproduce, es a través del intento de mantener la homosexualidad "en el armario". Ello pareciera darse más frecuentemente entre quienes en el pasado sostuvieron relaciones de pareja heterosexuales, de las cuales nacieron hijos/as. La discriminación, el rechazo y los estigmas asociados a la homo-lesbo-transfobia siguen pesando en esta decisión. Ello podemos ilustrarlo a través de Pedro -un hombre de 34 años, estudiante de una carrera técnica y gerente de ventas de una tienda de retail - quien mantiene una relación con Mario de 39 años de edad, hace más de 3 años. Ambos viven junto al hijo adolescente de Pedro, y reciben la visita contaste de su hija de 12 años. Pedro, aunque en la actualidad manifiesta proyectarse a largo plazo con su actual pareja, por muchos años mantuvo su homosexualidad oculta, principalmente por el temor a ser juzgado por su familia y la sociedad. Tal fue la presión que sintió, que por mucho tiempo solicitó apoyo a psicólogos y psiquiatras.

"Yo soy gay de toda la vida, pero viví un tiempo en el closet, se podría decir. Netamente por un tema social, un tema social, que no, que encuentran que no es normal, como que el mundo te va a apuntar con el dedo. De hecho, yo estuve con psicólogos, psiquiatras, una pila de tonteras, porque no me asumía bien en el tema" (Pedro, 34 años).

Luego de decidir dejar de ocultar su homosexualidad, y comenzar una vida junto a Mario, el hijo mayor de Pedro decide irse a vivir con ellos. Esta situación, aunque alegraba profundamente a Mario, y recibía al joven como un hijo, también lo inquietaba. Temía que vivir con un niño fuera visto por sus vecinos/as como un acto que pudiera perjudicar su bienestar físico y emocional. Aquí el temor a ser acusado de actos sexuales en contra del niño es un temor verosímil, ya que sabemos que los prejuicios y estereotipos sobre la idoneidad de homosexuales y lesbianas, para participar en el cuidado de niños y niñas, es algo todavía muy 
Revista Punto Género N.ำ 9. Junio de 2018

ISSN 0719-0417 / 85 - 105

arraigado en nuestra sociedad.

"Es que la mayoría de la gente tiende a, o sea, la sociedad tiende mucho al gay como, así como el degenerado, el depravado, el pedófilo" (Mario, 39 años).

Respecto de lo anterior, son innumerables los estudios que contrarrestan a través de la evidencia empírica, las tesis vinculadas con que las personas homosexuales no pueden tener y criar hijos/ o hijas, apoyándose en ideas como que los homosexuales poseen más problemas mentales. Dichos estudios han podido confirmar, por un lado, que tanto hombres como mujeres homosexuales tienen las mismas capacidades parentales que hombres y mujeres heterosexuales. Por otro lado, también reconocen que padres o madres críen a sus hijos/as junto a parejas del mismo sexo, no afecta el desarrollo saludable de los menores (APA, 2005).

\subsection{Familias que participan en el movimiento LGBTI: entre la reproducción y el desacato de las normas de género}

Considerando lo anterior, surgió nuestra inquietud de incluir entre los participantes del estudio a familias homoparentales vinculadas de alguna forma a las prácticas políticas del movimiento LGBTI, organizaciones que integran y apoyan las luchas contra la heteronormatividad y la discriminación hacia las minorías sexuales. Imaginábamos que esa participación podía permitir alguna forma de reflexividad que cuestionara los mandatos de género tradicionales asociados a las representaciones de lo que significa ser familia. Lo que encontramos fue tanto la reproducción como el intento de redefinir o tensionar esos mandatos.

Por el lado de la reproducción del género hegemónico, al hacer un recorrido por los relatos de nuestros entrevistados/as encontramos discursos respecto de sus orígenes que dan cuenta de historias marcadas por la incomprensión e incluso el desconocimiento de su realidad por parte de sus familias y cercanos. Se manifiesta así un miedo al rechazo y un sentimiento de culpa por las posibles consecuencias que traería para sí mismos, y también para sus familias, revelar quienes son.

"Pero es más respecto que vayan a apuntar a mi familia por mi culpa. Y yo sé que si mi papá se llega a enterar en algún momento lo voy a matar y con esa cuestión, yo con eso no podría vivir" (Edith, 41 años).

En este caso, el temor se enmarca en un contexto de tradicionalismo religioso fuertemente arraigado, que no considera concepciones de familia que superen los objetivos que en sus orígenes más occidentales se le atribuye a dicha institución, y concibe la familia como una entidad exclusivamente heterosexual, que tiene entre sus funciones la procreación y el cuidado de los/as hijos/as. Edith, al momento de ser entrevistada, tenía 41 años de edad y un hijo adolescente de 13. Ambos conviven junto a Adriana de 21 años, con quien Edith cumpliría pronto 4 años de relación.

Edith proviene de una familia campesina, ligada fuertemente a la religión evangélica. Muy joven 
Revista Punto Género N.ำ 9. Junio de 2018 ISSN 0719-0417 / 85 - 105

fue enviada sola a la capital, con el objetivo de concluir su educación obligatoria. En la actualidad, es dueña de un ciber café, y junto a su pareja, participan como activistas del Movimiento de Liberación e Integración Homosexual (MOVILH). A pesar de llevar años trabajando en conjunto con esta organización y de generar lazos de amistad con miembros del movimiento, Edith aún mantiene la decisión de ocultar a su madre su homosexualidad y la relación que ella y su hijo mantienen con su pareja:

"Lo que le digan a mi familia es lo que me importa. Es que igual yo todavía tengo muchas cuestiones de la iglesia arraigadas en mí; esa cuestión de honra a tu padre y a tu madre" (Edith, 41 años).

Este temor hizo que, años antes de conocer a Adriana, Edith decidiera mantener oculta su orientación sexual hasta el punto de llevar adelante un matrimonio heterosexual. La gran presión que siente frente a la idea de revelar quien verdaderamente es a sus familiares, la ha llevado a que, hasta el momento de la entrevista, aun no haya tomado la decisión de manifestar a quienes considera más cercanos, su homosexualidad. Por otro lado, para la familia de Edith era fundamental que ella siguiera el tradicional camino del matrimonio y los/as hijos/as, entendiendo esto como destino ineludible de la mujer cristiana.

"Decidí casarme por la cuestión de la religión de mis viejos, para que dejaran de molestarme. Me molestaban porque ya tenía 24, 25 años y no me casaba. $O$ sea, y i¿cómo no les iba a dar un nieto?!” (Edith, 41 años).

Hasta el momento de la entrevista, Adriana, Edith y el hijo de esta última, fruto de su matrimonio anterior, viven juntos y comparten como familia. El adolescente nunca ha cuestionado la orientación sexual de su madre, ni las decisiones que ella ha debido tomar producto de este destino, ni menos la relación que en la actualidad mantiene con Adriana. No obstante, hasta el día de la entrevista. Adriana era presentada ante todos/as los/as demás, sólo como una inquilina en la casa de Edith. Entre cuatro paredes, ellos llevan una vida familiar plena y sin secretos, pero fuera de casa el discurso cambia y las posiciones disidentes parecen más lejanas.

La familia homoparental -de la que hoy Edith es parte- rompe con las cuestiones más tradicionales, al ser constituida por personas con una orientación no heterosexual, solteras o en pareja. En este sentido, revelar la homosexualidad ante los padres o hermanos representa a menudo "un forcejeo ansioso por hacer encajar el discurso de la identidad sexual (si no del sexo), en el dominio cultural de 'la familia'." (Weston, 2003: 78). El declarase homosexual ante un familiar de sangre hace cuestionar el amor incondicional y la solidaridad duradera considerados atributos característicos de los vínculos familiares. En este sentido:

"La revelación ante un familiar biológico produce un discurso destinado a revelar la 'verdad', no solamente acerca de la persona, sino acerca de sus relaciones de parentesco. Al final de lo que muchas lesbianas y gays imaginan como un largo viaje hacia el autoconocimiento, al decirte quién soy (en realidad), descubro quién eres (en realidad para mí)" (Weston, 2003: 78). 
Revista Punto Género N.ำ 9. Junio de 2018 ISSN 0719-0417 / 85 - 105

El caso de Edith nos permite ilustrar cómo, aún en personas con un gran sentido de la lucha por la igualdad y el reconocimiento de los derechos de las minorías sexuales, sigue presente la presión que suponen los mandatos tradicionales de género sobre la institución familiar. Así, la forma en la que se invisibilizan y ocultan las prácticas lésbicas ante la familia de origen viene a operar como una condición de posibilidad para la reproducción hegemónica del género heteronormativo.

Otro caso que permite ilustrar la reproducción, tiene que ver con la forma de concebir a la familia en términos de parentesco y lazos sanguíneos que vienen a definir quién es familia y quién no lo es. El convivir bajo un contexto en donde no existe un padre y/o una madre con la que se comparten lazos sanguíneos directos, cuestiona en algunos casos el concepto de familia basado exclusivamente en relaciones de amor y afecto mutuo. En el caso de Enrique - joven transformista de 26 años, padre de un hijo de 5, y miembro de la organización "Acción Gay" haber sido criado por sus abuelos debido a circunstancias que impidieron que su madre o padre se hicieran cargo de su cuidado, significó haber crecido bajo el alero de quienes no reconoce realmente como familia.

"Nací como en una familia súper disfuncional, mi mamá trabajaba en el comercio sexual, mi papá era un tipo de estos que gastaba su plata de mala forma. Yo me crie en una familia que no era mi familia. Me crié con mis abuelos" (Enrique, 26 años).

Tal forma de concebir a "la familia", asociada sólo a los padres biológicos, también puede ser entonces interpretada como otra forma de reproducción de las normas hegemónicas del género en tanto reguladoras de la institución familiar, de nuevo, incluso en quienes participan en prácticas políticas que buscan transformar el género y la heteronormatividad.

Una tercera figura a través de la cual interpretar cómo opera la reproducción del género tradicional, la identificamos en la forma de concebir los efectos que tendrían para sus hijos/as el vivir en familias homoparentales. Algo que, como vimos antes, está también presente en quienes no participan en ninguna organización vinculada al movimiento LGBTI. Así, por ejemplo, el mismo Enrique nos relató cómo, producto de una relación casual, se convierte en padre a los 21 años de edad, y aunque tiene clara su identidad homosexual, decide intentar mantener una relación sentimental con la madre de su hijo en aquella época. Esta decisión es tomada por Enrique creyendo que su hijo crecería y se desarrollaría de una mejor manera si veía juntos a su padre y su madre, figuras masculina y femenina que, en conjunto, representarían estabilidad y balance para el niño.

"Siempre yo pensé darle como la familia completa a Carlos porque nunca estuvo en mi mente estar como separados, para que él nos viera separados, porque eso igual a la larga al niño igual lo desbalancea un poco, emocionalmente" (Enrique, 26 años).

En este sentido, la prohibición de que parejas del mismo sexo puedan formar una familia y ser padres o madres, se relaciona con la creencia en la posibilidad de provocar un daño psicológico 
Revista Punto Género N.ำ 9. Junio de 2018

ISSN 0719-0417 / 85 - 105

en el niño.

"Se piensa que, al ser criados en hogares homoparentales, se harían fantasías equívocas sobre la diferencia de los sexos, lo cual afectaría sus posibilidades futuras para un encuentro fecundo con personas del otro sexo. Desde esta óptica, la parentalidad homosexual comprometería procesos psíquicos fundamentales" (Lamas, 2007: 8).

Esto se conforma a partir de la creencia que el padre y la madre biológicos son siempre los encargados de la crianza. Sin embargo, como mencionamos anteriormente, esto ha sido objetado por innumerables estudios que han demostrado que mujeres y hombres han logrado criar a sus hijos/as de forma autónoma, y que la ausencia del modelo tradicional de familia (biparental), no se relaciona en ningún caso con el desconocimiento de las diferencias sexuales o una distorsión de éstas. Cuando una pareja homosexual decide unirse y formar una familia, las funciones al interior de esta nueva organización se recrean de forma indiferenciada y se interceptan con la historia individual de cada uno/a. De la misma manera, cuando se desea tener hijos/as o ya se tienen gracias a una relación anterior:

"Se experimenta un cambio radical que conduce a la reestructuración de la cotidianeidad, de las tareas parentales, y se transita de ser pareja, a ser madres lesbianas o padres gays, en donde empiezan los acuerdos de la redefinición de roles, los cuales pueden verse como papeles intercambiables" (González, 2007: 29).

Con todo lo anterior, ¿Hay algo de desacato a las normas hegemónicas del género como reguladoras de los significados del ser familia? Sí, el caso de Marlene y su pareja Pilar nos permiten ilustrarlo. Ambas mujeres, de 31 años, decidieron tener hijos luego de 3 años de relación. Producto de un proceso de inseminación artificial, Marlene se embaraza de mellizos que, en el momento de la entrevista, ya tenían 3 años y medio de edad. Su participación en el movimiento surge en forma de protesta, cuando deciden hacer pública la reclamación de legitimidad de su familia, a través del reconocimiento por parte del Registro Civil, de la existencia de ambas madres, lo que se materializaría en que sus hijos pudieran llevar los apellidos de ambas mujeres. Esta petición fue negada por la institución, por lo que la pareja decidió acercarse a la organización Corporación Humanas, con el fin de llegar a instancias internacionales que obliguen al país a reconocer estas maternidades. Esto, considerando que en el caso de familias gays o lesbianas biparentales, legalmente sólo es reconocida la parentalidad biológica de la madre o el padre.

"Lo que queremos es que reconozcan a mi pareja legalmente como mamá. Como que hay, tiene dos aristas; las aristas prácticas, si me llega a pasar algo a mí, quedaría mi familia legalmente a cargo de los niños, y nosotros queremos que cualquier cosa quede mi pareja a cargo de los niños" (Marlene, 31 años).

En cuanto a las características que permiten a los/as entrevistados/as afirmar su condición de familia, es posible extraer de sus discursos, elementos vinculados a los afectos, la protección y 
Revista Punto Género N.ำ 9. Junio de 2018 ISSN 0719-0417 / 85 - 105

la compañía. Para ellos/as, los lazos creados a partir del cariño, la capacidad de entregarse mutuamente protección y el compartir la compañía de cada uno de sus miembros, son aspectos que permiten definir los lazos familiares. Asimismo, la familia se relaciona también con la decisión de desarrollar un proyecto de vida en común. En este sentido, dichos elementos superan los lazos biológicos o de sangre que tradicionalmente definen a la institución de la familia en su versión más normalizadora.

Las ideologías del parentesco gay desafían la creencia de que sólo la procreación instituye el parentesco, y que los lazos no sanguíneos o biológicos deben ser legitimados a través de un modelo biológico, o debe abandonarse la idea de adherir al estatus de parentesco. Así, "lo que está en juego aquí es el valor cultural otorgado a los lazos originados en la procreación, y el significado que el vínculo biológico confiere a las relaciones en un contexto dado" (Weston, 2003:67-68)

En esta ocasión, es Marlene quien decide llevar el proceso de embarazo, un camino que en ella considera natural, y que desde siempre quiso transitar en su desarrollo como mujer, independiente de su condición homosexual. En este sentido, considera que el convertirse en madre no es un destino natural para las mujeres, pero admite que, junto a su pareja, se sentían lo suficientemente preparadas para comenzar el camino de la maternidad lésbica unidas.

"Para mí es como un deseo, no sé, natural de ser mujer. O sea, no digo que todas las mujeres, para mí era un deseo, siempre me encantaron los niños. Como que nunca me cuestioné mucho que, por mi opción sexual iba a dejar de ser mamá. Yo dije, bueno, quizás la sociedad chilena todavía no está tan preparada, pero nosotras nos sentíamos preparadas para ser mamás" (Marlene, 31 años).

Una de las etapas que debe ser vivenciada por la familia es el vínculo con el entorno, particularmente, con las instituciones que educan a sus hijos/as. En el caso de Marlene y su pareja, el contar con los recursos económicos suficientes, les permitió buscar las opciones que consideraron mejores para el correcto desarrollo de sus hijos, en un contexto que los protegiera, resguardados de prejuicios y discriminaciones. En este sentido, al menos para los sectores sociales más modernizados, la crianza de los niños y niñas se convierte en un proceso sumamente elaborado, en donde son fundamentales el vínculo y el desarrollo temprano, en función de diversos factores.

"La subjetividad constituye el patrimonio más preciado, ya que la inserción social depende mucho más de los recursos de personalidad y capacitación y menos de los lazos de nacimiento característicos de las sociedades estamentarias (...) El valor creciente del bienestar subjetivo (...) va unido a la secularización de la cultura y la conciencia de la transitoriedad" (Burin y Meler, 1998:190)

En este caso, durante la búsqueda de un espacio adecuado para el desarrollo temprano de sus hijos, y a lo largo de todo su camino como familia, jamás negaron su condición como tal, ni su estatuto de madres. De igual forma, perciben que para sus hijos esta realidad cotidiana es tan natural, que lo enfrentan sin tapujos y exponen su realidad con total normalidad. 
Revista Punto Género N.ำ 9. Junio de 2018 ISSN 0719-0417 / 85 - 105

“Nosotros siempre cuando íbamos a entrevistas decíamos, 'oye, somos dos mamás'. En verdad siempre lo hicimos en todas partes, desde que nacieron hasta que a todas partes donde vamos con ellos siempre (...). El otro día en un cumpleaños, me iba yendo, estaba yo con ellos y como que la mamá del cumpleaños le dice: 'oye, tu sorpresa', y le paso un volantín a uno y le dice: 'ah, para que lo armes con tu papá'. Así que él se da vuelta y le dice: 'oye, es que no tengo papá', pero súper bien. $Y$ ellos, como que han tenido que llevar fotos de la familia y todos sus compañeros saben que ellos tienen dos mamás y muchos les dicen a sus mamás: 'oye, yo quiero tener dos mamás"” (Marlene, 31 años).

La existencia cierta de familias homosexuales, permite cuestionar los supuestos básicos que, tanto el sentido común como las teorías científicas, han formulado en cuanto a la sexualidad y el género. "Se entiende comúnmente que la identidad de género se funda en la diferenciación complementaria que hay entre los sexos, con una hembra y un macho, dispuestos biológicamente para dar origen a un nuevo ser" (Robaldo, 2011: 173). No obstante, la homoparentalidad posee un sentido distinto al concepto de parentesco, asociándolo al género, ya que ambos son construidos, son un hacer, como performatividad (Robaldo, 2011).

Este tipo de familia se repite también en Javiera de 39 años, su hija de 8, y Mariana de 26 años de edad, con quien lleva, al momento de la entrevista, 6 años de relación y algunos menos de convivencia. En este caso, fue Javiera quien tomó la decisión de ser madre a través de técnicas de reproducción asistida, estando aun soltera. Luego de haber nacido su hija, conoce a Mariana, con quien entabla una relación seria, y decide iniciar una vida en común junto a su hija. La relación de Mariana con la hija de Javiera, desde un comienzo fue fluida y cercana, y en la actualidad la niña reconoce a ambas mujeres como miembros fundamentales de su familia.

"Ella expresa su felicidad, nos ama a las dos. Si discutimos dice 'no peleen, no discutan' nos dice a nosotras, porque, aunque tengamos muchas similitudes, igual tenemos opiniones muy distintas (...), entonces a veces chocamos en ese sentido $y$ ella al tiro: 'Ya, no, no más' (Javiera, 39 años).

Como muchas, esta pareja quiso llevar su reclamo a instancias que van más allá de la transmisión de un discurso, y lograron unir la protesta con su deseo de manifestar y legitimar su relación de amor. Esto, a través de las acciones generadas por la ONG de origen francés "Todos Unidos por la Igualdad", y su campaña por la legalización del matrimonio en países donde esta unión aun es negada. Gracias a esta campaña, Javiera y su pareja pudieron casarse bajo la ley belga a través de un sistema de videoconferencia, años antes que surgiera en Chile la ley que aprueba el Acuerdo de Unión Civil. Para esta familia, dicha ceremonia significó más que la demostración de su afecto, y representó también un llamado rabioso al Gobierno a respetar y legitimar estas relaciones unidas por el amor, en pos de terminar con la vulneración de sus derechos.

"Ellos están haciendo una campaña global en todos los países donde está prohibido para poder mandar un claro mensaje al Gobierno: 'mira, estamos casando a sus ciudadanos con nuestras leyes extranjeras. Nosotros avalamos este amor, 10 
respetamos, de hecho, lo oficializamos con jueces y con un alcalde. Sin embargo, ustedes no, son incapaces de ver que pocas personas, su gente está siendo vulnerada'. Ese fue el mensaje que queríamos dar" (Javiera, 39 años).

Aunque el cariño, la protección, la compañía y el deseo de desarrollar un proyecto de vida en común son elementos que destacan en el discurso de los entrevistados/as respecto de lo que la familia es para ellos/as, es posible entender que estas características siempre están insertas en un contexto de amor mutuo, que busca distanciarse de las nociones más tradicionales del amor como control.

"Bueno, es simple, porque nos amamos, porque tenemos un proyecto de vida, porque la Ana está siendo guiada por las dos, porque luchamos las tres juntas, porque la Ana no hace diferencia entre ninguna de las dos, nosotras tampoco con ella y como cualquier familia compuesta de personas que se aman y, que por ese vínculo que se llama amor, deciden luchar, deciden vivir, deciden disfrutar de ese amor, vivirlo" (Javiera, 39 años)

"Ni tu ni yo, eh, tratamos de vivir una vida tradicional, ni controladora ¿cierto? Nos amamos y punto. $Y$, nos amamos y eso es todo" (Mariana, 26 años)

\section{Algunas Conclusiones}

A lo largo de las ideas expuestas anteriormente, es posible dar cuenta de la existencia de múltiples trayectorias sobre cómo se llegan a armar diversas formas de familias homoparentales.

Analizando los discursos de nuestr@s entrevistad@s, pudimos observar que, tanto en quienes no tienen ninguna relación con el movimiento LGBTI, como en quienes sí participan de él, hay casos donde la verdad respecto de su orientación homosexual sigue oculta por el temor a las consecuencias que podría conllevar ese reconocimiento.

Las costumbres más conservadoras, y las tradiciones religiosas de las familias más creyentes, son marcas que, a pesar de la libertad que los individuos expresan, muchas veces no son posibles de abandonar por completo. Sobre todo, aquellas vinculadas con los aspectos más tradicionales ligados a lo que "ser hombre" y "ser mujer" significan hoy, en una cultura marcadamente heteronormada y machista. Lo anterior, permite entender que, el pertenecer a un movimiento reivindicatorio, participar en organizaciones como las mencionadas anteriormente y luchar por el reconocimiento de este tipo de derechos, no es garantía de que quien pelee lo haga a través de todas las áreas de su vida, asumiendo por ejemplo una identidad homosexual ante sus familiares y amigos. Así, a pesar del camino ganado en el reconocimiento de derechos de las personas LGBTI, aún se percibe en ellos el impacto que supone haberse formado en una sociedad fuertemente patriarcal, homofóbica y heteronormativa. Son estas cargas, sociales y culturales, las que todavía llevan a muchas personas a ocultar su condición homosexual frente a sus más cercanos, obligándolos, en 
muchos casos a "intentar" llevar una vida más tradicional ligada a la heterosexualidad. Esto, como una forma de resguardar su intimidad de posibles cuestionamientos y reproches, pero también por ser una manera de acercar a sus hijos o hijas a una forma de familia más tradicional, algo además condicionado a la clase social.

Además de querer conocer diferentes trayectorias de familias homoparentales, en este artículo buscábamos interpretar los relatos sobre dichas trayectorias desde la pregunta por cómo el género hegemónico se reproduce o transgrede, y cómo ello se vincula con la participación en prácticas políticas como la participación en organizaciones y colectivos vinculados al movimiento LGBTI. Al respecto, y tratándose de un estudio cualitativo, más que conclusiones, nos interesa cerrar con ciertas hipótesis a partir de nuestra lectura del material, que permitan abrir nuevas preguntas para seguir investigando.

La forma en que el género hegemónico se reproduce, está vinculada muy fuertemente con la manera de concebir las condiciones que garantizan el bienestar de los/as hijos/as, ya sea para darles lo que asumen como estabilidad emocional, para evitar reproducir en sus hijos/as la discriminación que los adultos han vivido o, para garantizarles el contacto con lo que se asume son las imágenes masculinas y femeninas correctas. Las prácticas de quienes aquí nos hablan dan cuenta que, aunque los sujetos convivan dentro de un contexto familiar subalterno - una familia homoparental - constantemente buscan adherirse al modelo de familia más tradicional y normalizado. Así, hay quienes siguen esforzándose por cumplir con el canon de armar una familia, llegando a fingir ser una familia nuclear heterosexual, cuando ambos padres son homolesbosexuales, lo que deviene en una performatividad que supone simular una normalidad imposible de encarnar.

Otra forma en que la norma hegemónica se reproduce, es a través de las estrategias de ocultamiento de la homosexualidad por la discriminación, el rechazo y los estigmas asociados a la homo-lesbo-transfobia. Aquí es donde la posibilidad de criar niños y niñas reactualiza el fantasma del abuso sexual como acto concatenado a la homoparentalidad. El temor de los padres/madres ya no es tanto por lo que ocurra con los hijos, sino por como ellos devienen en peligro para los/as padres/madres.

Estas formas de reproducción de las normas hegemónicas del género heteronormativo y sus justificaciones, aparecen no sólo en quienes no han tenido experiencias de reflexividad crítica sobre las mismas, a partir de prácticas de politización como es la participación en colectivos y organizaciones que trabajan contra la discriminación sexual. También quienes sí participan en dichas prácticas, mantienen la lógica del ocultamiento de la homosexualidad por temor a las consecuencias que ello acarrearía para los hijos y para evitar supuestos daños a las familias de origen. La posibilidad del daño a miembros de las familias - hijos, padres y hermanos - opera entonces como un recurso que moviliza la reactualización imperfecta de las normas hegemónicas.

Con todo, entre quienes participan en el movimiento LGBTI, encontramos prácticas que tensionan o desacatan las normas hegemónicas del género heteronormativo. Los dos casos que lo ilustran se caracterizan por tratarse de maternidades lesbianas asistidas 
Revista Punto Género N.ำ 9. Junio de 2018 ISSN 0719-0417 / 85 - 105

tecnológicamente. No sabemos si se trata de un patrón, pero lo dejamos planteado como posibilidad.

A su vez, es en ellas donde más se visibiliza lo que en el debate teórico anterior mostramos acerca de la transformación de la familia, entendida más que en su sentido normativo y de parentesco, como un espacio donde cada vez más se releva la importancia de los afectos. Nos parece relevante destacar además que, en estos intentos de desacato al género hegemónico, una estrategia importante ha sido la propia norma en su versión jurídica, ya sea reclamando el derecho a que ambas madres tengan reconocido dicho estatuto o reivindicando el derecho a casarse.

Queremos destacar esto último porque pese a que nos situamos desde un feminismo más bien posestructuralista, en la línea de Butler, ello no supone desconocer la relevancia que siguen teniendo las demandas del feminismo de la igualdad, en este caso, llevado al plano de las demandas por igualdad de derechos legales para familias homoparentales. Esto, además, cobra sentido con la forma de entender la institución familiar y los movimientos sociales feministas y de las disidencias sexuales, que también mostramos en el apartado teórico: politizar las formas de ser familia es una manera de encarnar los derechos asociados a la ciudadanía íntima (Plumer, 2003).

Finalmente, intentamos mostrar que efectivamente la sola existencia de familias homoparentales viene a cuestionar los supuestos básicos que sobre la sexualidad y el género. Y, como adelantamos con Robaldo (2011), la homoparentalidad posee un sentido distinto al concepto de parentesco, asociándose mucho más al de género construido en un hacer que es siempre performativo. No obstante, logramos comprender también que ello no garantiza un desacato al orden hegemónico del género, particularmente en su sentido heteronormativo, incluso cuando hay participación en prácticas políticas que deconstruyen tales hegemonías. Una vez más, como hemos aprendido con el feminismo post-estructuralista, se trata de disputas siempre contingentes.

\section{Bibliografía:}

APA, American Psychological Association (2005): Lesbian \& gay parenting. Disponible en: http://www.apa.org/pi/lgbt/resources/parenting-full.pdf

Bestard Camps, Joan y Roigé Ventura, Xavier (2014): "Noves famílies, noves identitats: una recerca sobre les transformacions de la família a Barcelona". Revista d'etnologia de Catalunya Vol. 0, Núm. 39, p. 204-208.

Burin, Mabel y Meler, Irene (1998): Género y Familia: poder, amor y sexualidad en la construcción de la subjetividad. Buenos Aires. Ediciones Paidós. 
Revista Punto Género N.ำ 9. Junio de 2018 ISSN 0719-0417 / 85 - 105

Butler, Judith (2006): "Regulaciones de género" en Revista de Estudios de Género La ventana, N.o 23, [On line]. Disponible en: http://www.redalyc.org/articulo.oa?id=88402303

Casado, Elena (2003): "La emergencia del género y su resignificación en tiempos de lo "post"”, en Revista Foro interno. $\mathrm{N} .{ }^{\circ}$ 3, [On line]. Disponible en: https://revistas.ucm.es/index.php/FOIN/article/viewFile/FOIN0303110041A/8143

Cruz, María Angélica (2015): Articulaciones entre género y memoria social sobre la dictadura cívico-militar chilena desde las prácticas políticas del presente. Proyecto Fondecyt 11150115. Postulación a convocatoria 2015, con financiamiento de la Comisión Nacional de Ciencia y Tecnología.

González, María de Jesús (2007): La representación social de las familias diversas: Ley de sociedades de convivencia. Revista El Cotidiano, N. ${ }^{\circ} 22$ [On line]. Disponible en: http://redalyc.uaemex.mx/pdf/325/32514604.pdf

Gonzálvez Torralbo, Herminia. (2013): "La producción científica sobre la familia en Chile: Miradas desde la antropología feminista". La ventana. Revista de estudios de género, 4(38), 88119.

Haraway, Donna (1995): Ciencia, ciborgs y mujeres. La reinvención de la naturaleza. Madrid. Ediciones Cátedra.

(2004): Testigo_Modesto@Segundo_Milenio: HombreHembra@ Conoce Oncoratón (R). Feminismo y tecnociencia. Cataluña, España. Editorial UOC

Jociles Rubio, María Isabel y Rivas Rivas, Ana María (2017): "Cambios en la concepción y representación del parentesco a raíz del uso de las técnicas de reproducción asistida con donante." Ankulegi. Revista de Antropología Social 20: 63-78

Lamas, Marta (2007): "Algunas reflexiones relativas al derecho a decidir sobre el propio cuerpo" en Astelarra, Judith (2007) Género y Cohesión social. Fundación Carolina CeALCI. N. ำ 16, [On line]. Disponible en: https://www.fundacioncarolina.es/wp-content/uploads/2014/08/DT16.pdf

MOVILH (2014): XIII Informe Anual de Derechos Humanos de la Diversidad Sexual en Chile: Historial anual de las minorías sexuales (Hechos 2014). Disponible en: http://www.movilh.cl/documentacion/2014/XIII-Informe-de-DDHH-MOVILH-2014.pdf

Ortiz Ruiz, Francisca y Gonzálvez Torralbo, Herminia (2017): Brechas y contradicciones entre la familia definida por la Ley y las familias en Santiago de Chile: miradas desde la antropología a partir de la dicotomía biología versus elección. Rumbos TS. Un espacio crítico para la reflexión en Ciencias Sociales, (16), 53-76. 
Revista Punto Género N.ำ 9. Junio de 2018 ISSN 0719-0417 / 85 - 105

Pichardo, José Ignacio (2009): (Homo) sexualidad y familia: cambios y continuidades al inicio del tercer milenio. Política y sociedad, ISSN 1130-8001, págs. 143-160.

Plummer, Ken (2003): "La cuadratura de la ciudadanía íntima. Algunas reflexiones preliminares" en Osborne y Guasch (2000) Sociología de la sexualidad, p. 89-102. Madrid, España: Centro de Investigaciones Sociológicas (CIS) - Siglo XXI

Robaldo, Marcelo (2011): "La homoparentalidad en la deconstrucción y reconstrucción de familia. Aportes para la discusión", en Revista Punto Género $N^{\circ} 1$. Disponible en: http://www.revistas.uchile.cl/index.php/RPG/article/viewFile/16859/17559

Romero, Carmen (2006): "Articulaciones identitarias: prácticas y representaciones de género y «raza»/etnicidad en «mujeres inmigrantes» en el barrio de Embajadores (Madrid)". Tesis doctoral sin publicar. Universidad Complutense de Madrid, España.

Ruiz, Jorge (2009): Análisis sociológico del discurso: métodos y lógicas en revista Forum: Qualitative social research, $\mathrm{N}^{\circ} 2$, [On line]. Disponible en: http://digital.csic.es/bitstream/10261/64955/1/Art\%C3\%ADculo\%20FQS\%20\%28espa\%C3\%B10 \%29.pdf

Sarti, Cintia (1998): "Familia, Apertura al Otro. Seminario Familia y Jóvenes. Fundación W.K. Kellogg”. Iniciativa para el Desarrollo de Jóvenes en América Latina y el Caribe. pp. 13-19

Thurler, Ana Liési (2008): "Más allá de las relaciones patriarcales de género. Parentalidades ciudadanas en la hetero y en la homoparentalidad". Disponible en: http://www.redmasculinidades.com/resource/images/BookCatalog/Doc/00155.pdf

Valdés, Ximena et al. (2006): Puertas adentro. Masculino y femenino en la sociedad contemporánea. Santiago de Chile: Editorial LOM.

Vaggione, Juan Marco (2008): "Capítulo uno. Las familias más allá de la heteronormatividad" en Motta y Sáez (eds.) La Mirada de los Jueces: sexualidades diversas en la jurisprudencia latinoamericana. Tomo II, p. 67-87. Bogotá, Colombia: Siglo del Hombre Editores, Red Alas.

Weston, Kath (2003) Las familias que elegimos: lesbianas, gays y parentesco. Barcelona, España: Plaza de edición. 